\title{
Elaboração de um instrumento para avaliar motivos que podem levar à evasão na educação superior em enfermagem: um estudo metodológico
}

\begin{abstract}
Elaboration of an instrument to evaluate reasons for a possible dropout in graduation degree nursing courses: a methodological study Elaboración de un instrumento para evaluar los motivos que pueden llevar a la deserción en la educación superior en enfermería: un estudio metodológico
\end{abstract}

LARISSA MERINO DE MATTOS

https://orcid.org/0000-0003-2139-5278

Universidade Federa do Rio Grande

Escola de Enfermagem

Núcleo de Estudos e Pesquisas em Saúde

Rio Grande, RS, Brasil

EDISON LUIZ DEVOS BARLEM

https://orcid.org/0000-0001-6239-8657

Universidade Federal do Rio Grande

Escola de Enfermagem

Departamento de Enfermagem e Obstetrícia

Rio Grande, RS, Brasil

SIMONÍ SARAIVA BORDIGNON

https://orcid.org/0000-0003-2039-1961

Universidade Federal do Rio Grande

Escola de Enfermagem

Núcleo de Estudos e Pesquisas em Enfermagem e Saúde

Rio Grande, RS, Brasil

JAMILA GERI TOMASCHEWSKI-BARLEM

https://orcid.org/0000-0001-9125-9103

Universidade Federal do Rio Grande

Escola de Enfermagem

Departamento de Enfermagem

Rio Grande, RS, Brasil

JANAÍNA SENA CASTANHEIRA

https://orcid.org/0000-0002-8300-698X

Universidade Federal do Rio Grande

Escola de Enfermagem

Departamento de Enfermagem e Obstetrícia

Rio Grande, RS, Brasil

SABRINA SANTOS DA ROCHA

https://orcid.org/0000-0001-9815-0899

Universidade Federal do Rio Grande

Faculdade de Enfermagem

Núcleo de Estudos e Pesquisas em Enfermagem e Saúde

Rio Grande, RS, Brasil 
Resumo: Objetivou-se elaborar um instrumento para avaliar os motivos que podem levar à evasão nos cursos de graduação em enfermagem. Tratou-se de estudo metodológico, seguindo cinco etapas para a elaboração de instrumentos de aferição. Participaram 182 estudantes de uma universidade pública. A coleta de dados ocorreu em agosto de 2018 e a análise deu-se a partir de estatística descritiva. Foi elaborado um instrumento composto de 24 questões, cujos fatores foram relacionados ao curso; universidade; professores e colegas; pessoais e/ou sociais; familiares; e referentes à profissão.

Palavras-chave: Enfermagem. Educação. Educação superior. Evasão escolar. Estudantes de enfermagem.

Abstract: The objective was to develop an instrument to assess the reasons that can lead to dropout in undergraduate nursing courses. It was a methodological study, following five steps for the elaboration of measurement instruments. 182 students from a Public University participated. Data collection took place in August 2018 and the analysis was based on descriptive statistics. An instrument composed of 24 questions was elaborated, whose factors were related to the course; university; teachers and colleagues; personal and/or social; relatives; and referring to the profession.

Keywords: Nursing. Education. Higher Education. School dropout. Nursing students.

Resumen: El objetivo fue desarrollar un instrumento para evaluar las causas que pueden llevar a la deserción en los cursos de licenciatura en enfermería. Fue un estudio metodológico, siguiendo cinco pasos para la elaboración de instrumentos de medida. Participaron 182 estudiantes de una Universidad Pública. La recolección de datos twvo lugar en agosto de 2018 y el análisis se basó en estadísticas descriptivas. Se elaboró un instrumento compuesto por 24 preguntas, cuyos factores estaban relacionados con el curso; Universidad; profesores y compañeros; personal y / o social; parientes y referente a la profesión.

Palabras clave: Enfermería. Educación. Educación universitaria. Abandono Escolar. Estudiantes de Enfermería.

\section{INTRODUÇÃO}

Observa-se nos últimos anos um cenário de crescimento no que diz respeito ao número de vagas dentro de Instituições de Ensino Superior (IES) que, em consequência disso, aumentam gradativamente a quantidade de estudantes no ambiente acadêmico e de situações oriundas desse complexo cenário (FITZGERALD et al., 2016). Com o desenvolvimento de escassos estudos e em limitadas áreas, pouco se conhece sobre a satisfação, insatisfação e a qualidade de vida dos acadêmicos ao entrarem em um curso de graduação, destacando-se a vivência de novas realidades nas quais os impactos ainda não são facilmente identificados (WAN et al., 2015; CHAN et al., 2019). 
Em consequência do aumento de vagas e dos novos desafios que se apresentam, também se verifica o aumento da evasão dos cursos de graduação nas universidades, evidenciando-se um fenômeno cada vez mais frequente e que gera preocupação para as instituições de ensino superior. Destaca-se, ainda, que o ingresso no ensino superior ainda é bastante distante para a maioria da população brasileira, embora as políticas públicas tenham ampliado o investimento nas universidades, implementando diversos programas para tornar o acesso à educação superior mais próximo e possível (DAVOK; BERNARD, 2016).

Entre esses programas, destacam-se: o Programa Universidade para Todos (ProUni), Fundo de Financiamento ao Estudante do Ensino Superior (FIES) para faculdades privadas, Exame Nacional do Ensino Médio (ENEM), Sistema de Seleção Unificada (SISU) tanto para ingresso nas universidades públicas quanto privadas, e Plano de Reestruturação e Expansão das Universidades Federais (REUNI). Diante disso, destaca-se o REUNI, que tem o objetivo de ampliar a permanência do acadêmico no ensino superior e a ocupação das vagas ociosas decorrentes da evasão (DAVOK; BERNARD, 2016).

Diversos fatores podem ocasionar a desistência da graduação pelo acadêmico, entre eles está o desconhecimento do curso escolhido, da realidade profissional, desgaste emocional por incertezas quanto à escolha da profissão, a tentativa de adaptação do curso de diferentes maneiras, dificuldade em relacionarse com docentes e colegas, entre outros. O processo de evasão pode ocasionar problemas na vida pessoal e profissional do acadêmico, contribuindo como fonte de estresse (HOEVE et al., 2017a).

Neste contexto, a evasão é conceituada oficialmente quando o aluno cancela a matrícula sem terminar o curso, quando abandona o curso sem cancelar a matrícula, (MELLO et al., 2016), ou quando o estudante muda de curso, dentro da mesma instituição ou parte para outra instituição (DAVOK; BERNARD, 2016). Desse modo, a evasão preocupa as instituições de ensino superior, pois provoca uma alta taxa de custos investidos pelo governo, tornando um gasto desnecessário e gerando ainda a ociosidade de vagas (DIOGO et al., 2016).

A evasão do curso de graduação em enfermagem pode estar relacionada ao baixo status, pouca procura pelo curso devido à falta de autonomia profissional, desvalorização da profissão e repetência em disciplinas, horário de trabalho incompatível com a graduação, estresse devido às aulas práticas e estágios curriculares, problemas financeiros e decepção com as expectativas ofertadas pelo curso (MELLO et al., 2016). Esses são alguns fatores igualmente desencadeantes e causadores de estresse no âmbito acadêmico em enfermagem e possivelmente colabora para o processo de evasão (KORHONEN et al., 2019). 
Ressalta-se, na literatura, que os eventos estressores dos quais os estudantes de enfermagem perpassam, geralmente são advindos do percurso durante a graduação, uma vez que estão constantemente em episódios de responsabilidade pela vida e a saúde dos indivíduos (CHAN et al., 2019). Como consequência do grau de insatisfação, tais influências podem impactar na evasão (ROOS et al., 2016). Apesar de se reconhecer de forma ampla as situações estressoras que perpassam os ambientes de formação na área de enfermagem, as quais podem contribuir para o processo de abandono do curso, ainda faltam subsídios concretos e objetivos que norteiem a construção de estratégias efetivas para o enfrentamento do fenômeno da evasão.

Dessa forma, buscando consolidar o reconhecimento dos principais desencadeadores do fenômeno da evasão em cursos de graduação em enfermagem, esse estudo justificou-se em virtude da escassez de pesquisas na área (TOMASCHEWSKI-BARLEM et al., 2014) e da inexistência de um instrumento específico para identificar as causas da evasão. Destaca-se que atualmente o curso de graduação em enfermagem da universidade em que ocorreu o estudo, possui uma taxa de 11,73\% de evasão, referente à taxa do ano de 2018. Neste contexto, foi objetivo deste estudo: elaborar um instrumento para avaliar os possíveis motivos que podem levar à evasão nos cursos de graduação em enfermagem.

Conforme apresentada a temática do estudo, cabe ressaltar a relevância da ampliação de estudos na área da educação para que sejam implementadas estratégias para diminuir a evasão nas IES. A coleta de dados da pesquisa ocorreu em uma universidade específica, delimitando o estudo, porém, o instrumento construído é especificamente para o curso de graduação em enfermagem, podendo ser aplicado em qualquer outro curso de graduação em enfermagem, por ser de cunho educacional geral.

A pesquisa foi realizada em uma universidade pública federal no ano de 2018, e a metodologia utilizada deu-se a partir de cinco etapas do estudo metodológico explicadas a seguir na seção dos métodos (DEVELLIS, 2017). Após a metodologia aplicada, apresentam-se os tópicos mais importantes nos resultados e discussões acerca da elaboração do instrumento. Por fim, as considerações finais, um apanhado do estudo aplicado. 


\section{MÉTODOS}

A pesquisa foi desenvolvida a partir de cinco etapas propostas nas diretrizes internacionais para obtenção de instrumentos de avaliação, com o objetivo de preparar métodos de obtenção, organização e análise de dados, a partir da elaboração, adaptação, validação e avaliação de instrumentos (DEVELLIS, 2017). Foram realizadas as seguintes etapas para construção do instrumento: revisão bibliográfica em base de dados para confirmação da inexistência de um instrumento específico, de motivos que podem levar à evasão para o curso de graduação em enfermagem.

A revisão bibliográfica ocorreu no mês de abril de 2018, utilizando as bases de dados Scielo e MedLine; coleta de prováveis questões que poderiam levar os estudantes à evasão do curso; síntese de aproximação e agrupamento das questões; formulação da versão de avaliação do instrumento e construção do modelo final do instrumento com 24 questões.

O cenário do estudo foi uma universidade pública federal brasileira, em um curso de graduação em enfermagem. A coleta de dados ocorreu no mês de agosto de 2018 e foi realizada em todos os dez semestres do curso. Foi solicitado o agendamento com os professores das disciplinas para que a coleta fosse realizada dentro da sala de aula e no horário de aula. Foram convidados 260 acadêmicos que estavam efetivamente matriculados no ano de 2018 no curso, atendendo aos seguintes critérios de inclusão: ser acadêmico regular do curso, estar presente em aula no dia da coleta de dados.

Os critérios de exclusão dos participantes se restringiram a não ser aluno regular do curso ou estar em afastamento ou regime de estudo domiciliar no momento de coleta de dados. Dessa forma, após ler e assinar o Termo de Consentimento Livre e Esclarecido (TCLE), 182 estudantes participaram da pesquisa. A pesquisa deu-se em dois momentos, o primeiro, aplicando-se um questionário para a caracterização e perfil dos estudantes de enfermagem e, o segundo, os estudantes poderiam escrever até dez situações que poderiam levá-los a evadir.

O processo de análise dos dados foi executado em duas etapas: a primeira, realizando a sumarização e agrupamento das questões indicadas pelos estudantes em enunciados únicos; a segunda, realizando a distribuição de frequência e análise descritiva dessas questões de caracterização. Foi incluída como questão, no instrumento, todo enunciado que fosse proposto por mais de $10 \%$ dos estudantes; dessa forma, a partir dos 182 respondentes, cada questão contemplada ao menos 19 vezes, foi incluída na versão final do instrumento. O processo de análise dos dados, obtidos através da aplicação dos questionários, foi realizado 
a partir do software Statistical Package for Social Sciences (SPSS). Foram mantidos e respeitados os preceitos da resolução nº 466/12 do Conselho Nacional de Saúde, com aprovação do Comitê de Ética em Pesquisa local, no 68/2018 (CAAE: 91980418.8.0000.5324).

\section{RESULTADOS}

Entre os 182 respondentes, $169(92,9 \%)$ eram do sexo feminino e $13(7,1 \%)$ do sexo masculino. A idade variou de 17 a 50 anos, sendo a média bimodal de 21 e 22 anos. A maioria dos estudantes eram solteiros (79,2\%); 16,5\% afirmaram ser casados; 3,8\% possuíam união estável; e 0,5\% eram divorciados. Verificou-se a predominância de $81,9 \%$ de estudantes que afirmaram não possuir filhos, enquanto 15,9\% relataram ter filhos, e 2,2\% não responderam à questão.

$\mathrm{O}$ ano de ingresso no curso variou de 2008 a 2018, tendo um predomínio do ano de 2018 com 52 (28,6\%) estudantes. Após, 2017 com 33 (18,1\%); em seguida, 2015 com 30 (16,5\%); e 2014 com 27 (14,8\%) estudantes. Sobre a forma de ingresso na universidade, 166 (91,3\%) estudantes entraram pelo Sistema de Seleção Unificada (SISU/ENEM); 8 (4,4\%) pelo Processo Seletivo de Vagas Ociosas; 1 (0,5\%) pelo PEC-G (Programa de Estudantes-Convênio de Graduação); 3 (1,6\%) pelo Processo seletivo Específico para Indígenas; e 4 (2,2\%) pelo Processo Seletivo Específico para Quilombolas.

Verificou-se que $126(69,2 \%)$ estudantes não frequentaram outra instituição de nível superior, e 56 (30,8\%) já frequentaram. Entre esses estudantes que cursaram outra IES, 15 (8,2\%) cursavam enfermagem, 7 (3,8\%) cursavam outro curso da área da saúde, e 34 (18,8\%) estavam matriculados em cursos de outras áreas. Além disso, verificou-se que, desses estudantes, 29 (15,9\%) eram advindos de universidades públicas e 27 (14,3\%) de universidades privadas.

Sobre o grau de informação dos estudantes de enfermagem acerca do curso, obteve-se o seguinte resultado: 4 (2,2\%) estudantes não obtiveram nenhuma informação acerca do curso quando escolheram cursar enfermagem; 61 (33,5\%) estudantes tinham pouca informação do curso; 78 (42,9\%) consideravam-se informados; 28 (15,4\%) muito informados; e 11 (6\%) totalmente informados. Sobre a questão de desistência do curso, 95 (52,2\%) estudantes referiram que já pensaram em desistir, e $87(47,8 \%)$ referiram que nunca pensaram em desistir do curso. Ainda, verificou-se que 139 (76,4\%) estudantes conheciam alguém que já desistiu do curso, e 43 (23,6\%) não conheciam ninguém.

Sobre a primeira opção de curso dos estudantes, $135(74,2 \%)$ responderam enfermagem, $47(25,8 \%)$ responderam outro curso. Desses 47 estudantes, $27(14,8 \%)$ responderam que a outra opção de curso seria medicina; $9(4,9 \%)$ 
responderam outro curso da área da saúde; e 11 (6,1\%) responderam cursos de outras áreas. Entre os 182 estudantes, 33 (18,1\%) reprovaram somente uma vez em alguma disciplina; 20 (11\%) reprovaram duas vezes; 14 (7,7\%) reprovaram mais de duas vezes; e $115(63,2 \%)$ nunca reprovaram em nenhuma disciplina. E, por fim, sobre a questão do grau de relacionamento com os docentes do curso, $39(21,4 \%)$ responderam que o relacionamento com os docentes era muito bom, $117(64,3 \%)$ responderam que era bom, $26(14,3 \%)$ responderam ser regular.

Sobre os auxílios recebidos pela universidade, 103 (56,8\%) estudantes referiram não receber qualquer tipo de auxílio; 9 (4,9\%) recebiam auxílio financeiro; $5(2,7 \%)$ recebiam auxílio transporte; $3(1,6 \%)$ recebiam auxílio alimentação; 1 $(0,5 \%)$ recebia auxílio moradia; $18(9,9 \%)$ recebiam mais de um auxilio, entre eles: $32(17,6 \%)$ recebiam auxílio transporte e alimentação, e 11 (6,0\%) recebiam auxílio financeiro, transporte e alimentação. Dos 182 estudantes, 141 (77,5\%) referiram não trabalhar; $29(15,9 \%)$ referiram trabalhar na área da saúde; 10 (5,5\%) referiram trabalhar em outra área; e 2 não responderam a esse questionamento. Referente às atividades extracurriculares, $116(63,8 \%)$ estudantes não participavam; 27 (14,8\%) eram bolsistas voluntários; e $39(21,4 \%)$ eram bolsistas remunerados.

Dentre os 182 estudantes, vinte acadêmicos estavam cursando o primeiro semestre do curso de graduação em enfermagem; trinta e um cursavam o segundo; vinte e quatro estavam no terceiro; outros vinte e quatro cursavam o quarto semestre; treze acadêmicos no quinto; outros treze no sexto semestre; dezenove no sétimo semestre; onze acadêmicos no oitavo; dezessete cursavam o nono; e dez acadêmicos cursavam o décimo semestre.

Para a elaboração do instrumento de pesquisa, seguiram-se as cinco etapas indicadas para a obtenção de questionários, as quais nortearam a apresentação dos resultados. A primeira etapa consistiu em uma revisão bibliográfica em bases de dados nacionais e internacionais, scielo e MedLine, determinando, assim, a confirmação da inexistência de um instrumento que pudesse avaliar possíveis motivos de abandono nos cursos de graduação em enfermagem. Foram utilizados os descritores em português: Enfermagem, educação, educação superior, evasão escolar e estudantes de enfermagem. Essa etapa possibilitou o aprofundamento teórico na literatura disponível, necessário para buscar os motivos que podem levar um estudante à evasão do curso e também para a elaboração das questões diante dos enunciados apresentados durante a coleta de dados.

A segunda etapa iniciou através da coleta de prováveis questões que poderiam conduzir a evasão na perspectiva dos estudantes de graduação em enfermagem. Para tanto, todos os estudantes matriculados nos dez semestres do curso receberam um instrumento de coleta de dados que continha questões de caracterização e uma tabela numerada com dez espaços em branco, para 
que pudessem escrever de uma até dez possíveis situações e/ou motivos que poderiam resultar na evasão do curso de graduação em enfermagem, tanto na sua perspectiva pessoal quanto na observação da experiência compartilhada com outros colegas.

Após a coleta das possíveis questões, os enunciados produzidos pelos estudantes foram classificados e sumarizados, numerando-os para obter uma melhor organização dos dados. Dessa forma, a transcrição de todas as respostas dos 182 participantes totalizou o levantamento de 869 enunciados, destacando que não era necessário preencher os dez motivos, ficando a critério do estudante.

Na terceira etapa, foi possível realizar a aproximação das respostas obtidas através dos questionários para determinar o formato da medição. Dessa forma, buscando aproximar os 869 enunciados em grupos semelhantes, foram realizadas séries de leituras que visaram aproximar possíveis semelhanças, gradativamente, reduzindo a amplitude de respostas. Nessa etapa, foram empregadas estratégias de obtenção de convergência de enunciados através da aproximação do núcleo de sentido de cada uma das prováveis situações indicadas pelos participantes. Dessa forma, o total de 869 foi sintetizado em 81 enunciados.

De posse dos 81 enunciados, verificou-se que diversas relações de semelhança teórica ainda eram existentes, observando-se situações comuns que poderiam ser expressas por diferentes enunciados. Dessa forma, realizou-se uma segunda síntese com a aproximação das 81 questões de acordo com seu conteúdo e aproximação com a revisão bibliográfica. Ainda nesta etapa, foi computado o número de vezes que cada uma das prováveis questões apresentou.

Visando reduzir o provável instrumento a um número mais adequado de questões, buscando não tornar o mesmo extenso e exaustivo, foi estabelecido um critério de seleção dos enunciados, estabelecendo-se que cada enunciado para tornar-se uma provável questão, deveria atingir 10\% de frequência na amostra, ou seja, do número total de 182 respondentes, se um enunciado não fosse citado pelo menos 19 vezes dentre o número total de respondentes, o mesmo não seria indicado para a versão final do instrumento. Desse modo, questões com maior número de citações e com aderência teórica ao referencial foram classificadas como categorias e questões próximas a essa categoria foram classificadas como subcategorias.

$\mathrm{Na}$ quarta etapa, a fase pré-final da construção do instrumento, foi realizada a apresentação da proposta final de instrumento para três experts na temática, sendo todos enfermeiros docentes com titulação de doutorado e experiência comprovada em curso de graduação. Suas sugestões foram apontadas no próprio instrumento proposto e a síntese delas formou a proposta final de 
questionário. Ocorreram pequenas adaptações de linguagem e não houve sugestão de inclusão de enunciados, o que possibilitou uma versão final do instrumento que apresentou 24 questões.

Na quinta e última etapa, houve a diagramação e construção do modelo final do instrumento, com a inclusão dos itens de caracterização da amostra, inclusão de um enunciado conceitual do tema e um parágrafo indicando a forma de procedimento para responder às questões. A escala proposta adotou como critério de resposta uma escala Likert de 5 pontos que definem o grau de concordância ou discordância dos respondentes com cada uma das questões propostas, ou seja, o quanto cada uma das questões contribui com a possibilidade de evasão de um curso de graduação em enfermagem. Variando de 1 a 5 , foram utilizados sequencialmente os termos: não contribui, contribui pouco, nem contribui e nem não contribui, contribui muito, contribui completamente. Abaixo, segue a figura 1, um fluxograma para melhor entendimento das cinco etapas realizadas na pesquisa.

Figura 1 - Fluxograma das cinco etapas realizadas no estudo.

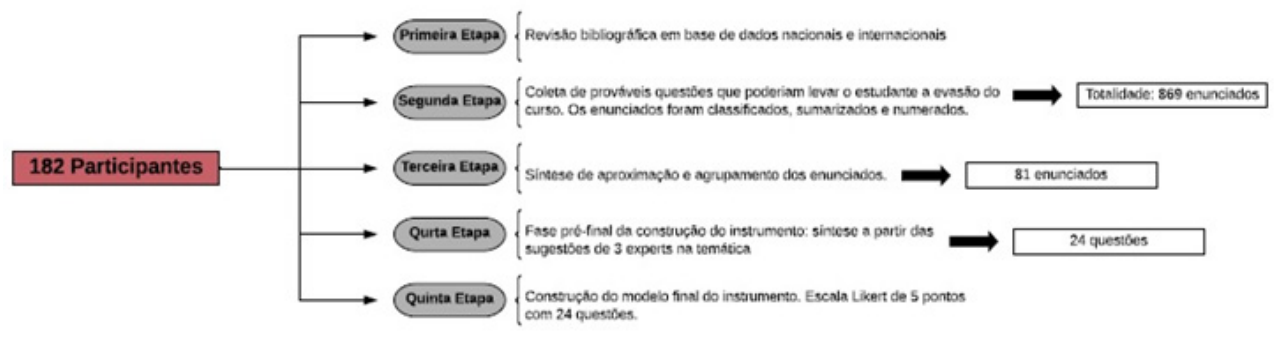

Fonte: elaboração própria.

Visando analisar a convergência teórica entre as questões, diante da apresentação final do instrumento, foi possível agrupar as 24 questões em seis grandes fatores de análise, denominados neste estudo como: fatores atrelados ao curso; fatores relacionados à universidade; fatores referentes a professores e colegas; fatores pessoais e/ou sociais; fatores familiares; e, por fim, fatores referentes à profissão enfermagem.

Primeiramente, o fator atrelado ao curso englobou sete questões da escala construída: frustração com o curso; aprovação em outro curso de interesse; dificuldade com as disciplinas; aulas pouco atrativas; reprovação e retenção nas disciplinas; extensa carga horária e sobrecarga de atividades acadêmicas. $\mathrm{O}$ segundo, fator relacionado à universidade, foi constituído de duas questões: 
dificuldade da adaptação ao ensino superior e ausência/precariedade de apoio, recursos e benefícios da universidade. $\mathrm{O}$ terceiro fator, denominado fatores referentes a professores e colegas, abrangeu três questões: dificuldade de convívio com colegas; dificuldade de convívio com professores e assédio moral de docentes.

O quarto fator, denominado como fatores pessoais e/ou sociais, englobou seis questões do instrumento: falta de recursos financeiros; problemas de saúde (físicos); problemas emocionais e psicológicos; oportunidade/necessidade de emprego; gravidez/ter filhos e não conseguir conciliar a rotina diária de trabalho com a faculdade. O quinto fator estabelecido foi denominado como fatores familiares, apresentando três questões: problemas familiares; morar longe da família e mudança de cidade. O sexto e último fator foi denominado fatores referentes à profissão enfermagem, contendo igualmente três das questões: desmotivação por falta de informação do trabalho do enfermeiro; baixa valorização/autonomia/remuneração da profissão e medo de exercer a profissão.

Salienta-se que esse estudo foi realizado em uma população específica, sugerindo-se que mais pesquisas acerca de possíveis motivos que poderiam levar o estudante a evadir do curso sejam abordadas com ênfase em estratégias que busquem trazer o estudante para o meio acadêmico novamente. Ressaltase que as questões originárias do instrumento poderão ser objeto de estudos posteriores. $\mathrm{O}$ instrumento construído possibilitará a obtenção de importantes informações sobre a população acadêmica, uma vez que pode alertar os docentes, as coordenações de cursos e as instituições de ensino superior para evitar que a evasão se efetive, possibilitando a construção de estratégias de enfrentamento mais eficazes.

\section{DISCUSSÃO}

A caracterização sociodemográfica da amostra permitiu identificar as características da amostra obtida, verificando-se aproximação das características desses dados com outros estudos, cuja amostra foi composta por estudantes de graduação em enfermagem, com predominância de estudantes do sexo feminino, adultos jovens, solteiros e sem filhos (CHAN et al., 2019; TOMASCHEWSKIBARLEM et al., 2014; WAN et al., 2015).

De acordo com os prováveis fatores gerados a partir das questões elencadas pelos estudantes, foi possível perceber que os fatores atrelados ao curso aparentaram estar relacionados com a não identificação com o curso ou com a área de atuação, com a complexidade, incompatibilidade ou decepção com o curso, por não ser a primeira opção no momento da escolha da profissão. Contudo, o vínculo 
acadêmico entre colegas e seus mestres torna-se essencial para a permanência no curso, assim, buscando a adaptação necessária para a opção de curso escolhida, construindo aspirações da profissão futura a ser exercida (TARTAVOULLE et al., 2018).

Em um estudo realizado com acadêmicos do curso de farmácia e do curso de enfermagem, em uma universidade de Mato Grosso, foi evidenciado que a enfermagem é o principal curso a estar em contato constante com pacientes, sua dor, sofrimento e morte, o que requer constante apoio e integração entre colegas e docentes para o enfrentamento dessas situações (MESQUITA et al., 2016). Desse modo, a evasão torna-se um meio de refúgio para acadêmicos que não conseguem criar ou estabelecer esse vínculo com seus colegas e docentes, por timidez ou por não conseguir se aproximar da prática diária.

Pode ser percebido certo despreparo para cursar o ensino superior por parte dos participantes deste estudo, que associado à incerteza de que profissão seguir, favorece os estudantes a possibilidade de evasão. É possível compreender que a escolha do futuro profissional possa gerar medo, ansiedade e insegurança no estudante, assim como sentimentos de culpa de ter tomado a decisão precipitada, ou até mesmo equivocada, de ter de seguir a profissão e não obter satisfação na atividade exercida, gerando também a insatisfação profissional (PORTO; SOARES, 2017, TURNER; MCCARTHY, 2016).

A não escolha da enfermagem como primeira opção de curso foi evidenciada neste estudo como importante causa da evasão. Estudo realizado com estudantes do curso de enfermagem de uma instituição de ensino superior localizada na região do Cariri Cearense corrobora com os dados apresentados, enfatizando que a enfermagem também não foi referida como primeira opção de curso (BORGES; BRITO; CHAGAS, 2016).

Este cenário parece ter sido agravado ao longo dos últimos anos com a adesão das universidades ao Sistema de Seleção Unificada (SISU/ENEM). É possível perceber que com esse sistema, os estudantes colocam distintas opções de curso que desejam, com a possibilidade de, com o passar dos dias, modifiquem até sua nota alcançar algum curso que possa ter acesso e, assim, ingressar na universidade, sem a convicção de que o curso escolhido será sua profissão no futuro próximo (SOUTO et al., 2018).

Ainda relacionado aos fatores que envolvem o curso, outra situação evidenciada como contribuinte para a evasão do estudante de graduação é a ausência de metodologias adequadas de ensino, destacando-se a ocorrência de aulas pouco atrativas e com aplicação de didáticas ultrapassadas, como mencionadas pelos estudantes dessa pesquisa. 
Em um estudo realizado com discentes de enfermagem da Universidade Federal de Pernambuco, foi evidenciado que 68,3\% dos discentes gostariam que fossem desenvolvidos outros tipos de metodologias de ensino, no entanto, não consideravam seus docentes instrumentalizados para essa modificação (SOUTO et al., 2018). Dessa forma, seria interessante que os docentes da educação superior refletissem sobre suas metodologias de ensino aplicadas em sala de aula, para que o processo de ensino-aprendizagem se torne mais efetivo para os estudantes de graduação, evitando o pensamento de evadir por não se adaptar ao novo contexto da universidade e curso escolhido (HOEVE et al., 2017b).

É perceptível neste estudo que a reprovação dos estudantes nas disciplinas pode revelar importante relação com a evasão, reconhecendo que o rendimento acadêmico está diretamente relacionado à continuidade do curso. Desse modo, o estudante que possui um baixo rendimento acadêmico pode vir a reprovar em alguma disciplina, podendo vir a evadir pelo fato de que com a repetência algumas disciplinas são pré-requisitos para outras, assim, o estudante reprovado não tem prioridade na escolha da matrícula, além do desestímulo por parte da dificuldade em alguma disciplina (WRAY et al., 2017).

Em um estudo realizado com 236 estudantes de enfermagem em uma instituição de ensino superior, os acadêmicos mencionaram a extensa carga horária e a sobrecarga de atividades acadêmicas como possíveis causas da evasão, dificultando o processo de aprendizagem e gerando ansiedade, pressão e autocobrança excessivas (COSTA et al., 2018). Os estudantes desta pesquisa também citaram, além dessas acima, a dificuldade de ter atividade de lazer, devido à falta de tempo para realizá-las. Dessa forma, a qualidade de vida dos estudantes vem sendo afetada devido ao excesso de trabalhos acadêmicos, exigências dos docentes e extensa grade curricular no curso de graduação em enfermagem (FREITAS et al., 2017).

$\mathrm{O}$ segundo conjunto de fatores apresentado, relacionado com a universidade, apresentou questões referentes à dificuldade de adaptação ao ensino superior e a ausência de apoio, recursos e benefícios da universidade. Os estudantes também mencionaram que foi identificada uma dificuldade de exercer atividades práticas de enfermagem nas localidades distantes da universidade, necessitando assim, de auxílio transporte. Estudos referem que os estudantes chegam à universidade pública, em muitos casos, com a necessidade de se manterem com algum tipo de bolsa ou auxílio financeiro ofertado pela instituição. Estes também se tornam essenciais para a sua permanência, visto que necessitam de transporte, alimentação, material didático, e muitos necessitam de moradia, por serem de outras cidades, entre outros custos que ultrapassam a renda familiar 
do acadêmico (AMBIEL; BARROS, 2018). Tais situações contribuem para um possível pensamento de evadir do curso de enfermagem e optar por um curso de um turno, que não gere tantos gastos para os estudantes.

O terceiro conjunto de fatores apresentado está relacionado com os professores e colegas, ou seja, enfatizando as dificuldades nas relações pessoais desenvolvidas nos ambientes de formação acadêmica. No estudo, em busca de possíveis fatores que levariam os estudantes a evadirem do curso, houve uma série de respostas tais como: não ter uma boa relação com os colegas e nem com professores. Entretanto, houve respostas enfatizando que nunca procuraram ter um bom convívio com os mesmos, o que dificulta a posição do professor.

Em um estudo realizado em um curso de gestão pública de uma instituição federal de educação, foi evidenciado que um dos fatores que contribui para os estudantes não evadirem do curso, está ligado ao bom convívio com colegas e professores, além da motivação da família no curso escolhido (BRUM; GAMENHA; PEREIRA, 2018). Para que os estudantes obtenham um bom desenvolvimento na graduação, torna-se relevante que o docente acompanhe o acadêmico tanto para sua frequência, dificuldades, quanto para seu currículo, incentivando-o cada vez mais a buscar atividades extracurriculares, projetos de pesquisa, extensão, entre outras atividades que contribuem para a formação (HIRCH et al., 2018).

O assédio moral dos docentes foi relatado pelos estudantes de enfermagem neste estudo, configurando-se como questão do instrumento final. Um estudo sobre assédio moral realizado com 18 estudantes de graduação em enfermagem, em uma instituição de ensino superior localizada na cidade de Maringá, evidenciou que o assédio moral está presente de forma marcante no cotidiano acadêmico, estudantes entrevistados afirmaram ter sofrido o assédio e presenciaram o assédio moral tanto com seus colegas quanto com os docentes. Os sentimentos relatados no estudo foram de inferiorização, exposição ao ridículo, perseguição, tristeza, raiva, desrespeito, entre outros sentimentos negativos que, consequentemente, transpareceram em suas vidas profissional e pessoal, afirmaram os estudantes (SCARDOELLI et al., 2017).

Outro dado de grande importância que pode levar o estudante a evasão do curso, diz respeito aos fatores pessoais e/ou sociais, incluindo problemas financeiros, emocionais e de saúde, necessidade de trabalhar, ou não conseguir conciliar a rotina diária com trabalho e faculdade. Além disso, a gravidez ou o fato de ter filhos foram mencionados como fatores que também contribuem para a evasão. 
Um estudo com 236 estudantes de enfermagem em uma instituição de ensino superior afirma que problemas de saúde vêm acompanhados da sobrecarga de atividades tanto extraclasse quanto atividades diárias, e a necessidade de trabalhar no turno inverso. Tais contextos podem ainda ser mais agravantes devido aos problemas financeiros, diante à fragilidade das políticas de permanência das universidades, citadas anteriormente (MACIEL; LIMA; GIMENEZ, 2016).

O contexto da saúde mental foi destacado neste estudo, evidenciando nos enunciados o quanto este interfere no rendimento acadêmico, no relacionamento com os colegas, professores e família, podendo levar o estudante à evasão do curso de graduação. Problemas de saúde também podem vir acompanhados de problemas emocionais e psicológicos, podendo vir a ser necessário o acompanhamento psicológico, serviço implementado e ofertado por algumas instituições de ensino superior (COSTA et al., 2016). Cabe ressaltar a emergência das IES, por possuírem serviços de acompanhamento do acadêmico, visto que condições de saúde mental, como a depressão entre estudantes, vem a ser de grande risco; além da evasão, pode ocorrer danos irreversíveis.

Não conseguir conciliar a rotina diária de trabalho com a faculdade, mostrou-se, neste estudo, como importante fator que pode conduzir à evasão. Pode-se considerar que o tempo integral do curso, as atividades práticas, a articulação da teoria e prática demandam muito tempo do estudante, assim, não conseguindo obter um bom desempenho. Tais achados se aproximam dos dados de estudo desenvolvido com estudantes de graduação em enfermagem de uma instituição de ensino superior, que acrescentou ainda que no fim do curso, o trabalho de conclusão do curso também é um fator importante a ser mencionado, pois a sobrecarga de trabalhos, estágio e atividades extraclasses necessitam de atenção e dedicação dos estudantes (COSTA et al., 2018).

O quinto conjunto de fatores apresentado no instrumento proposto neste estudo está relacionado a fatores familiares, os quais envolvem transferência de cidade e faculdade, residir sozinho, morar longe da cidade natal e sentir falta de sua família. Fatores familiares podem gerar motivos para levar os estudantes à evasão do curso e entre eles, pode-se citar que residir em um local diferente ou mudar-se para um local distante do núcleo familiar pode ser uma situação delicada e complexa, devido o estudante estar fragilizado e residindo em outra cidade, em um ambiente totalmente novo, com colegas novos, com professores diversos, atividades obrigatórias e com alguns longos anos de permanência na universidade (COSTA; MOREIRA, 2016). 
As exigências da família, a pressão de entrar em uma universidade, a necessidade de escolha do curso, podem gerar grande desconforto nos estudantes, desencadeando ansiedade. As exigências familiares e aquelas impostas pelo mercado de trabalho aos novos profissionais, aliadas a incerteza de que serão absorvidos pelo mercado, podem também gerar desconforto nos estudantes de graduação que almejam tanto a aquisição de um emprego logo após a conclusão do curso (JESUS et al., 2015).

O último fator apresentado no estudo está relacionado aos desafios da futura profissão, destacando-se questões relacionadas à desmotivação por falta de informação do trabalho do enfermeiro, à baixa valorização, autonomia e remuneração da profissão e, por fim, o medo de exercer a profissão escolhida, o que pode levar o acadêmico a evadir do curso, por receio de como agir nas dificuldades, de como exercer a prática e o convívio com a equipe de enfermagem e paciente, englobando também a dificuldade de administrar psicologicamente a perda e a morte, o medo do mercado de trabalho e da realização de procedimentos complexos (JESUS et al., 2015).

Estudo realizado com coordenadores de 10 cursos de graduação em uma universidade pública brasileira, identifica que dentre os motivos que poderiam levar os estudantes de graduação à evasão do curso, estão: a desmotivação e o desinteresse pelo curso, devido a diversos fatores relacionados, tais como: tempo insuficiente para lazer, reprovações frequentes em uma disciplina, tarefas relacionadas à vida pessoal, diminuindo o tempo para os estudos e remuneração inadequada para a profissão (JESUS et al., 2015).

Salienta-se a falta de estudos internacionais acerca da temática na literatura, talvez devido a diferentes sistemas de ingressos em outros países. Ressalta-se novamente que este estudo foi realizado em uma população específica, em uma universidade federal pública brasileira, tornando limitados os dados coletados. Dessa forma, espera-se que este estudo possa abrir novas perspectivas para ampliação do tema na área da educação e da saúde, assim, diminuindo o número de evasões em cursos de instituições de ensino superior.

\section{CONSIDERAÇÕES FINAIS}

A evasão é um complexo fenômeno cujas causas de origem exigem um minucioso e atento olhar por parte das instituições de ensino superior. Entre os possíveis motivos que poderiam levar os acadêmicos à evasão do curso, podem ser citadas as condições financeiras, a sobrecarga de atividades, a falta de tempo para lazer, a não identificação com o curso, a reprovação e a repetência, a extensa carga horária, ausência de apoio da universidade, entre outros. 
A partir das questões, construíram-se fatores para contemplar os enunciados. Os resultados do presente estudo são importantes, a fim de elucidar as diferentes formas que o acadêmico pode pensar em evadir do curso, assim, alertando docentes e coordenações de curso para que se amparem os estudantes. Os fatores que fizeram parte da construção do instrumento foram relacionados a seis áreas identificadas através da sumarização e agrupamento das questões indicadas pelos estudantes em enunciados únicos e análise descritiva. Assim, foram identificados seis domínios de influência para a evasão do curso de graduação em enfermagem, são eles: fatores atrelados ao curso, fatores relacionados à universidade, fatores referentes a professores e colegas, fatores pessoais e/ou sociais, fatores familiares e fatores referentes à profissão enfermagem.

Torna-se relevante destacar que os referidos fatores perpassam questões íntimas com percepção única do indivíduo, entretanto o conhecimento da existência desses em uma dada população estudantil permite tanto aos docentes quanto a coordenação de curso, e as instituições de ensino superior, traçar estratégias para superar a evasão, como, por exemplo, acompanhamento psicológico para estudantes vulneráveis à evasão ou para aqueles que buscam ajuda; rodas de conversa; acolhimento de novos estudantes e re(acolhimento) dos acadêmicos, sendo essas ações específicas para cada contexto identificado.

O objetivo do estudo foi alcançado com êxito, visto que a elaboração do instrumento específico para o curso de enfermagem foi obtida a partir dos próprios estudantes. Cabe ressaltar que mais estudos e pesquisas nessa temática devem ser abordados, para sua ampliação, pois todo produto de uma investigação deve ser entendido de modo provisório.

\section{REFERENNCIAS}

AMBIEL, R. A. M.; BARROS, L. O. Relações entre evasão, satisfação com escolha profissional, renda e adaptação de universitários. Psicologia: teoria e prática, São Paulo, v. 20, n. 2, p. 254-267, ago. 2018.

BORGES, A. M. M.; BRITO, R. S.; CHAGAS, S. N. F. Percepção dos estudantes de graduação em enfermagem sobre o trabalho do enfermeiro. Revista de Enfermagem do Centro-Oeste Mineiro, v. 6, n. 3, p. 2421-2429, 2016.

BRUM, D. V.; GAMENHA, D. E. S.; PEREIRA, M. B. S. Panorama da evasão e permanência no ensino superior no instituto federal de Rondônia-Porto Velho zona norte. Brazilian Applied Science Review, v. 2, n. 1, p. 357-369, 2018. 
COSTA, C. R. B. et al. Percepções de discentes de enfermagem sobre fatores geradores de estresse durante a graduação. Revista da Rede de Enfermagem do Nordeste, v. 19, p. 1-9, 2018.

COSTA, M. et al. Associação entre estresse e variáveis sociodemográficas em estudantes de enfermagem de uma instituição do paraná. Revista de Enfermagem da UFJF, v. 2, n. 1, p. 9-19, 2016.

COSTA, M.; MOREIRA, Y. B. Saúde mental no contexto universitário. Blucher Design Proceedings, v. 2, n. 10, p. 73-79, 2016.

CHAN, Z. C. Y. et al. Curriculum design and attrition among undergraduate nursing students: A systematic review. Nurse education today, v. 74, p. 41-53, 2019.

DAVOK, D. F.; BERNARD, R. B. Avaliação dos índices de evasão nos cursos de graduação da Universidade do Estado de Santa Catarina-UDESC. Avaliação: Revista da Avaliação da Educação Superior, v. 21, n. 2, 2016.

DEVELLIS, R. F. Scale development: theory and applications. 4. ed. Copyright. Sage; 2017.

DIOGO, M. F. et al. Percepções de coordenadores de curso superior sobre evasão, reprovações e estratégias preventivas. Avaliação: Revista da Avaliação da Educação Superior, v. 21, n. 1, p. 125-151, 2016.

FITZGERALD, H. E. et al. The centrality of engagement in higher education. Journal of Higher Education outreach and engagement, v. 20, n. 1, p. 223244, 2016.

FREITAS, A. M. C. et al. Percepções de estudantes de enfermagem referente à qualidade de vida na trajetória acadêmica. Revista de Enfermagem da UFSM, v. 7, n. 2, p. 153-166, 2017.

HIRSCH, C. D. et al. Fatores percebidos pelos acadêmicos de enfermagem como desencadeadores do estresse no ambiente formativo. Texto \& Contexto Enfermagem, v. 27, n. 1, 2018. 
HOEVE, Y. T. et al. Nursing students' changing orientation and attitudes towards nursing during education: A two year longitudinal study. Nurse education today, v. 48 , p. 19-24, 2017 a.

HOEVE, Y. T. et al. Dreams and disappointments regarding nursing: Student nurses' reasons for attrition and retention. A qualitative study design. Nurse education today, v. 54, p. 28-36, 2017 b.

JESUS, I. S. et al. Vivências de estudantes de graduação em enfermagem com a ansiedade. Revista de enfermagem UFPE, v. 9, n. 1, p. 149-155, 2015.

KORHONEN, V. et al. Understanding the multidimensional nature of student engagement during the first year of higher education. Frontiers in psychology, v. $10,2019$.

MACIEL, C. E.; LIMA, E. G. S.; GIMENEZ, F. V. Políticas e permanência para estudantes na educação superior. Revista Brasileira de Política e Administração da Educação-Periódico científico editado pela ANPAE, v. 32, n. 3, p. 759781, 2016.

MELLO, S. P. et al. Um panorama da evasão no sul do Brasil: Estudando os cursos superiores de tecnologia em uma universidade pública federal. Congressos CLABES, 3 nov. 2016. Disponível em: http://revistas.utp.ac.pa/index.php/ clabes/article/view/997. Acesso em: $1^{\circ}$ set. 2020.

MESQUITA, A. M. et al. Depressão entre estudantes de cursos da área da saúde de uma universidade em Mato Grosso. Journal Health NPEPS, v. 1, n. 2, p. 218-230, 2016.

PORTO, A. M. S.; SOARES, A. B. Diferenças entre expectativas e adaptação acadêmica de universitários de diversas áreas do conhecimento. Aná. Psicológica, Lisboa, v. 35, n. 1, p. 13-24, mar. 2017.

ROOS, E. et al. Attrition of undergraduate nursing students at selected South African universities. Curationis, Pretoria, v. 39, n. 1, p. 1-8, 2016.

SOUTO, R. Q. et al. Metodologias de ensino-aprendizagem sob a perspectiva de discentes de enfermagem. Revista da Rede de Enfermagem do Nordeste, v. 19, 2018. 
SCARDOELLI, M. G. C. et al. Vivência dos acadêmicos de enfermagem diante das ocorrências de assédio moral. Rev. enferm. UFPE on line, v. 11, n. 2, p. 551-558, 2017.

TARTAVOULLE, T. et al. Predictors of Success in BSN Students. International journal of nursing education scholarship, v. 15, n. 1, 2018.

TOMASCHEWSKI-BARLEM, J. G. et al. Síndrome de Burnout entre estudantes de graduação em enfermagem de uma universidade pública. Revista LatinoAmericana de Enfermagem, v. 22, n. 6, p. 934-941, 2014.

TURNER, K.; MCCARTHY, V. L. Stress and anxiety among nursing students: A review of intervention strategies in literature between 2009 and 2015, Nurse Education in Practice, v. 22, p. 21-29, 2016.

WAN, C. D. et al. Academic culture in Malaysia: Sources of satisfaction and frustration. Asia Pacific Education Review, v. 16, p. 517-526, 2015.

WRAY, J. et al. Factors affecting the programme completion of pre-registration nursing students through a three year course: A retrospective cohort study. Nurse education in practice, v. 24, p. 14-20, 2017.

\footnotetext{
Larissa Merino de Mattos

Enfermeira graduada pela Universidade Federal do Rio Grande - FURG. Membro do Núcleo de Estudos e Pesquisas em Saúde - NEPES/FURG. Rio Grande, RS, Brasil. Bolsista do Programa Institucional de Bolsas de Iniciação Científica (PIBIC) do Conselho Nacional de Desenvolvimento Científico e Tecnológico (CNPq) no período de 2016 a 2019. Especialista em Enfermagem em Ginecologia e Obstetrícia pela Faculdade FUTURA/FAVENI. Mestranda do Programa de Pós-Graduação em Enfermagem (PPGENF) da Escola de Enfermagem (EENF) da Universidade Federal do Rio Grande - FURG. E-mail: merinolarissa@hotmail.com
} 


\section{Edison Luiz Devos Barlem}

Possui graduação em Enfermagem e Obstetrícia pela Universidade Federal do Rio Grande (2006), mestrado em Enfermagem pela Universidade Federal do Rio Grande (2009) e doutorado em Enfermagem pela Universidade Federal do Rio Grande (2012). Atualmente diretor da Escola de Enfermagem da FURG; é membro da Sociedade Brasileira de Bioética, membro - International Association for Education in Ethics, membro da Associação Brasileira de Enfermeiros de centro cirúrgico, recuperação anestésica e centro de material e esterilização SOBECC. É professor Associado da Universidade Federal do Rio Grande. Professor Permanente dos programas de Pós-graduação em Enfermagem e do Programa de Pós-graduação em Ciências da Saúde da FURG. Tem experiência na área de Enfermagem, com ênfase em Ética, atuando principalmente nos seguintes temas: ética de enfermagem/saúde, tecnologias educacionais no campo da formação de enfermagem/saúde, exercício de poder e a relação com a organização do trabalho, judicialização em saúde, sofrimento moral, advocacia em saúde e sensibilidade moral. E-mail: ebarlem@gmail.com

\section{Simoní Saraiva Bordignon}

Graduada em Enfermagem pela Universidade Federal do Rio Grande - FURG (2010). Mestre em Ciências pelo Programa de Pós Graduação em Enfermagem (PPGEnf) - UFPel (2012). Doutora em Enfermagem pelo Programa de PósGraduação em Enfermagem -FURG (2016). Membro do Núcleo de Estudos e Pesquisas em Enfermagem e Saúde (NEPES). Atualmente é docente da Escola de Enfermagem (EEnf) - FURG, atuando nas disciplinas de Enfermagem na Saúde da Criança e Adolescente I (Graduação); Processo de enfermagem (Graduação); Estágios Supervisionado (Graduação). Pesquisadora do Núcleo de Estudos e Pesquisas em Enfermagem e Saúde (NEPES).E-mail: simonibordignon@gmail. com

\section{Jamila Geri Tomaschewski-Barlem}

Possui graduação em Enfermagem pela Universidade Federal do Rio Grande - FURG (2010). Mestre em Enfermagem pelo Programa de Pós-Graduação em Enfermagem (PPGEnf) - FURG (2012). Doutora em Enfermagem pelo PPGEnf-FURG (2014). Atualmente é docente da Escola de Enfermagem (EEnf) - FURG, atuando nas disciplinas de Enfermagem na Administração das Organizações de Saúde (Graduação); Enfermagem na Administração Hospitalar (Graduação); Organização do Trabalho da Enfermagem/Saúde (Mestrado); Ética no Trabalho da Enfermagem/Saúde (Mestrado/Doutorado). Pesquisadora do Núcleo de Estudos e Pesquisas em Enfermagem e Saúde (NEPES). Atuou como Coordenadora do Curso de Graduação em Enfermagem (2015-2017); Coordenadora Adjunta do Curso de Graduação em Enfermagem (2017-2019). Tem experiência na área de Enfermagem e Saúde, com ênfase em Educação e Organização do Trabalho da Enfermagem e Saúde, Ética na Enfermagem, Ética na Saúde, atuando principalmente nos seguintes temas: formação profissional na área da saúde, segurança do paciente e gestão de serviços de saúde, advocacia em saúde, problemas morais no trabalho da saúde. E-mail: jamila_tomaschewski@ hotmail.com 


\section{Janaína Sena Castanheira}

Graduação em Enfermagem e Obstetrícia pela Universidade Federal do Rio Grande (2002), Licenciatura em Enfermagem pela Universidade Federal do Rio Grande (2002), Mestrado em Enfermagem pela Universidade Federal do Rio Grande (2004), Especialização em Saúde Pública pelo Instituto Superior de Ensino, Pesquisa e Extensão (2006), Aperfeiçoamento em Vigilância Sanitária pela Fiocruz (2008). Possui Doutorado em Educação Ambiental pela Universidade Federal do Rio Grande (2011); Professor Associado I da Escola de Enfermagem FURG. Vice-Diretora da Escola de Enfermagem FURG. E-mail: janainasena@furg.br

\section{Sabrina Santos da Rocha}

Possui Bacharelado e Licenciatura em Enfermagem pela Universidade Federal de Pelotas (2007), Licenciatura Plena em História pela Universidade Federal de Pelotas (2002). Atualmente é enfermeira técnica administrativa em educação da Universidade Federal do Rio Grande, atuando na supervisão de estágio da Escola de Enfermagem. Especialização em Urgência e Emergência. Especialização em Centro Cirúrgico e Central de Material. Residência em Atenção Básica em Saúde Coletiva. Atualmente membro do Grupo de Pesquisa Núcleo de Estudos e Pesquisas em Enfermagem e Saúde- NEPES - FURG. Mestre pelo Programa de Pós-Graduação em Enfermagem (PPGENF) da Escola de Enfermagem (EENF) da Universidade Federal do Rio Grande - FURG. Doutoranda do Programa de Pós-Graduação em Enfermagem (PPGENF) da Escola de Enfermagem (EENF) da Universidade Federal do Rio Grande - FURG. E-mail: sabrinarochaenf@yahoo.com.br 